\title{
OBITUARY
}

\section{LIFE AND SCIENTIFIC ACTIVITY OF PROFESSOR M. V. SHIMANSKAYA (1922-1995)}

\author{
Ya. Stradyn', A. Anderson, and L. Leite
}

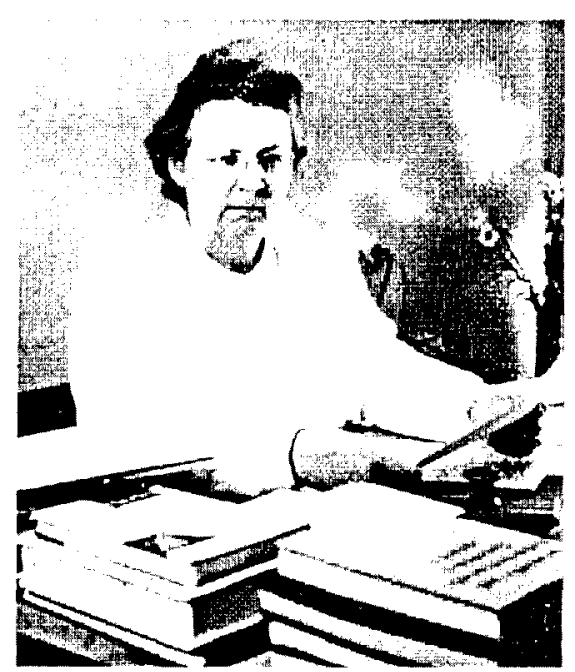

On July 10, 1995, after a long and serious illness, Maria Vladislavovna Shimanskaya - Honorary Member of the Latvian Academy of Sciences, Professor, Doctor of Chemistry - passed away. She was one of Latvia's most eminent chemists and pharmacists of recent decades, whose contribution to the region of catalytic reactions of heterocyclic compounds is difficult to exaggerate.

Maria Tarvid was born on April 23, 1922 at Daugavpils. After finishing at the Daugavpils high school she worked in her home town as probationer at the Zalessky pharmacy, and in 1942 she entered the pharmaceutical department at Latvian University. During the Second World War M. Tarvid was associated with the Polish Resistance Movement (the Kraiov Army). In April, 1943, she was arrested by the Hitlerites and placed in Daugavpils prison, and later she was placed in Stuthofsk concentration camp.

In 1945 M. Tarvid renewed her studies at the Chemical Faculty of Latvian State University, which she completed in 1948. having presented a thesis on the catalytic oxidation of furan.

After finishing at the university, M. Tarvid managed the analytical control laboratory of the Main Pharmaceutical Authority of the Latvian SSR and at the same time started post-graduate work.

In the spring of 1952, M. Tarvid, among three women chemists (É. Gudrinietse, M. Tarvid, and V. VitolaZelmene), defended for the first time in the history of Latvian science a candidate's thesis on heterogeneous catalysis, entitled "Investigations into the Oxidation of Furfural by Atmospheric Oxygen in the Vapor-Gas Phase at Mixed Vanadium Oxide Catalysts."

Together with S. A. Giller, G. Ya. Vanag, and S. P. Zaeva, M. V. Shimanskaya took part in the creation of the Institute of Organic Synthesis, Academy of Sciences of the Latvian SSR, and was the first long-standing (1957-1975) deputy director of scientific work. In 1959 she organized the first scientific-research laboratory of catalysis in Latvia - the Laboratory of Catalytic Processes and Synthesis of Monomers (more recently, the Laboratory of Catalytic Synthesis, Institute of Organic Synthesis, Academy of Sciences of the Latvian SSR). 
Shimanskaya created the Riga school of specialists in the region of heterogeneous catalysis, which includes five doctors and 17 candidates of chemical sciences

The fruitful scientific activity of M. V. Shimanskaya is illustrated by the number of her published papers - five monographs, 395 scientific articles, 279 papers at All-Union and international conferences, and 107 popular scientific articles.

The broad range of Shimanskaya's scientific interests include both investigations of reactions of practical importance - the oxidation of furan and furfural, the products from the processing of pentosan-containing material to maleic anhydride (a valuable monomer for the manufacture of plastics and intermediate in the synthesis of pesticides) - and the development of modern nontraditional methods of catalysis.

She paid special attention to the creation of new methods for the production of drugs based on heterocyclic compounds. Shimanskaya usually combined the solution of technological problems with the solution of theoretical problems of heterogeneous catalysis in the chemistry of heterocyclic compounds.

The researches conducted under Shimanskaya's leadership mainly touched upon three groups of catalytic reactions: oxidation; decarbonylation and hydrogenation; and cyclization with the elimination of polar functional groups. Catalytic vapor-phase oxidation reactions were investigated on examples of the oxidation of heterocyclic compounds (five-membered oxygen- and sulfur-containing heterocycles and six-membered nitrogen-containing heterocycles). Original vanadiummolybdenum catalysts, promoted by the oxides and salts of silver, phosphorus, titanium, and sodium and other elements, were created for the selective oxidation of furan compounds to maleic anhydride. The optimum $\mathrm{V}-\mathrm{Mo}-\mathrm{P}-\mathrm{Ti}-\mathrm{O}$ catalyst from the standpoint of activity and selectivity on aluminum gave a product yield at a level of $70 \%$ with a productivity of 20 g/liter h. The method for the production of maleic anhydride was protected by inventor's certificates (1963-1976). The world's first industrial production of maleic anhydride by the oxidation of furfural at the Riga paint plant was based on the created method (1963). For this set of researches a group of authors (M. V. Shimanskaya, V. A. Slavinskaya, and A. A. Avots) and a number of the workers at the plant were awarded a State prize of the Latvian SSR

A special position in the researches of Shimanskaya and her coworkers is occupied by the partial oxidation of the methyl derivatives of heterocyclic compounds to heteroaryl aldehydes, since these poorly available compounds are convenient starting materials for the synthesis of many medicines

In the case of methyl derivatives of the pyridine series it was established by kinetic, IR spectroscopic, $x$-ray spectroscopic, programmed thermal desorption, and quantum-chemical methods that the reactivity and reaction mechanism of the oxidation of six-membered nitrogen-containing methylheterocycles at $\mathrm{V}-\mathrm{Mo}-\mathrm{O}$ catalysts depends on the charge at the carbon atom of the methyl group being oxidized. In the case of a large positive charge, the heterocycle interacts with the catalyst by an oxidation-reduction mechanism and is oxidized selectively to the corresponding aldehyde with a yield of up to $60 \%$ and a productivity of $450 \mathrm{~g} / \mathrm{liter} \cdot \mathrm{h}$. Methylheterocycles with a small charge at the carbon atom of the methyl group are characterized by acid-base interaction and low selectivity for the formation of the aldehydes. It was also shown that the active centers on the surface of the $\mathrm{V}-\mathrm{Mo}-\mathrm{O}$ catalysts are formed during the oxidation of the methylheterocycles and contain vanadium atoms in various valences. Recommendations were put forward for the planned design of catalysts, depending on the structure of the compound being oxidized. Preparative methods were created for the production of aldehydes of the pyrimidine and pyrazine series by the oxidation of the respective methylazines

On the basis of the researches carried out under Shimanskaya's leadership, a technology was developed for the production of pyridinecarbaldehydes, and this was introduced at a pilot plant of the Institute of Organic Synthesis, Academy of Sciences of the Latvian SSR, and at the Kiev reagent, indicator, and analytical product plant.

A second group of reactions investigated under Shimanskaya's leadership included the decarbonylation and hydrogenation of aliphatic, aromatic, and heterocyclic aldehydes in the vapor-gas phase. It was shown that furfural and methylfurfural are decarbonylated selectively in the presence of $\mathrm{Cr}-\mathrm{Zn}-\mathrm{Mn}$ catalysts, promoted by the salts of alkali metals The $\mathrm{Pd} / \mathrm{C}$ and $\mathrm{Pd} / \mathrm{Al}_{2} \mathrm{O}_{3}$ catalysts are the most suitable for the hydrogenation of these compounds to the corresponding alcohols. Technologies were developed for the industrial and semindustrial production of furan, 2-methylfuran, and 2,5dimethylfuran. In the presence of a copper-chromite catalyst, 5-methylfurfural is hydrogenated with $95 \%$ selectivity to 2,5 dimethylfuran, while pyridinecarbaldehydes are hydrogenated to pyridylcarbinols with yields of $65-94 \%$

In the sixties, under the guidance of Shimanskaya, investigations were begun into the cyclization of diamines, amino alcohols, and alcohols, with the aim of obtaining $\mathrm{N}$ - and $\mathrm{O}$-containing compounds.

In the presence of traditional dehydration catalysts, such as the oxides of aluminum, titanium, tungsten, thorium, and zirconium, aluminosilicates, and phosphates, cyclization in the vapor-gas phase with the removal of the polar functional groups $\left(\mathrm{OH}, \mathrm{NH}_{2}\right)$ takes place nonselectively. Calculation of the formation energy of the transitional complexes shows that 
the probability of deamination (dehydration) and hydrogenolysis at the $\mathrm{C}-\mathrm{N}(\mathrm{C}-\mathrm{O})$ bonds is comparable. On account of this, mixtures containing up to 20 products were obtained as a result of the reaction. Standard-free methods of GLC were developed for the determination of the composition of these mixtures.

At catalysts modified by acidic additives and also in the presence of the individual acid anhydrides or their mixtures. when acid centers of the Brønsted type predominate on the surface, the protonation of the $\mathrm{NH}_{2}(\mathrm{OH})$ group, accompanied by weakening of the $\mathrm{C}-\mathrm{N}(\mathrm{C}-\mathrm{O})$ bond and the elimination of $\mathrm{NH}_{3}\left(\mathrm{H}_{2} \mathrm{O}\right)$ molecules, is most likely. At oxide catalysts, the surface of which mostly contains Lewis acid centers, the specific weight of the dehydrogenation and hydrogenolysis process increases. This secures the production (e.g., from diethylenetriamine) of such compounds as pyrazine and its derivatives. At $\mathrm{Al}_{2} \mathrm{O}_{3}$ with additions of $\mathrm{P}_{2} \mathrm{O}_{5}, \mathrm{MoO}_{3}$, and $\mathrm{CuO}$, the yield of pyrazine amounts to $42 \%$, with the total content of the pyrazine compounds at a level of $75 \%$. If $\mathrm{P}_{2} \mathrm{O}_{5}$ is replaced by $\mathrm{B}_{2} \mathrm{O}_{3}$, the content of pyrazine in the mixture of pyrazine bases is increased by four times.

The range of heterocyclic compounds that Shimanskaya and her students were able to obtain by the cyclization of polyfunctional aliphatic compounds is extremely large. For example, aziridine was obtained from 1,2-diaminoethane with $\mathrm{WO}_{3}+\mathrm{P}_{2} \mathrm{O}_{5}$ or $\mathrm{WO}_{3}+\mathrm{B}_{2} \mathrm{O}_{3}+\mathrm{CoO}$ as catalysts (yields 42 and $48 \%$ ). At a copper-chromite catalyst promoted by calcium in an atmosphere of hydrogen, 1 -amino-2-propanol is converted with a $95 \%$ yield into 2,5-dimethylpyrazine, and in a stream of air it is converted into 1 -aminoethyl-2-methylaziridine (78\% selectivity)

In the presence of the catalysts $\mathrm{P}_{2} \mathrm{O}_{5}, \mathrm{WO}_{3}$, and $\mathrm{WO}_{3}+\mathrm{SiO}_{2}, 1$-amino-4-butanol forms pyrrolidine with $100 \%$ selectivity. At $\mathrm{P}_{2} \mathrm{O}_{5}, 1,4$-butanediamine is converted into pyrrolidine (yield $96 \%$ ), and at $\mathrm{WO}_{3}$ on kaolin it is converted into pyrroline (yield $85 \%$ ). It was possible to obtain tetrahydrofuran with $100 \%$ selectivity from 1,4-butanediol at $\mathrm{SiO}_{2}$ or at $\mathrm{WO}_{3}$ and its mixtures with $\mathrm{SiO}_{2}$ and $\mathrm{B}_{2} \mathrm{O}_{3}$. whereas $95-97 \%$ of $\gamma$-butyrolactone was formed as a result of dehydrocyclization in the presence of copper oxide or chromite.

Liquid-phase deaminocyclization at metals takes place selectively. Piperazine is formed with $76 \%$ selectivity from diethylenetriamine at Raney nickel or at Raney nickel promoted with 3\% of titanium at a hydrogen pressure of 40-100 atm In the presence of nickel deposited on the oxides of metals of groups V and VI, the yield of piperazine amounts to $90 \%$ of the theoretically possible yield.

Under Prof. Shimanskaya's leadership, such methods of catalysis as phase-transfer and metal-complex catalysis were widely used simultaneously with classical methods. On account of their simplicity and effectiveness, these methods met the demands of modern technology and made it possible to intensify the processes of synthesis and to increase their regio- and stereoselectivity and also the product yields. With the use of quaternary ammonium salts or crown ethers as catalysts under the mild conditions of phase-transfer catalysis, it was possible to realize such difficult reactions as the alkylation of azoles (yields $80-98 \%$ ), the O-alkylation of furan, thiophene, and pyridine derivatives (yields $30-70 \%$ ), the $\mathrm{N}$-formylation of cyclic secondary amines (yields up to $86 \%$ ), the synthesis of $\mathrm{N}$ - and S-containing carboxylic acids by the oxidation of the corresponding methyl derivatives (yields 30-75\%), the reduction of heteroarylaldehydes to carbinols (yields $70-90 \%$ ), the synthesis of trichloropyridylcarbinols and trichloromethylazines (yields $28-60 \%$ ), and the nucleophilic substitution of halogencontaining compounds.

The combination of phase-transfer and metal-complex catalysis in a two-phase system proved very fruitful. On account of their bifunctionality, the complexes of the ions of transition metals with lipophilic cations make it possible to realize the effective hydrogenation of double and triple bonds or hydrosilylation with the simultaneous addition of : $\mathrm{CCl}_{2}$. The use of the complexes of transition metals with the chiral derivatives of pyridine led to the production of optically active alcohols of the pyridine series.

Professor Shimanskaya investigated the structure of catalysts and the mechanism of their action in close cooperation with the leading specialists of the former USSR in the field of catalysis - Prof. I. I. Ioffe, L. Ya. Margolis, O. V. Krylov. G. P. Korneichuk, and others. She actively participated in the work of the Scientific Council on Catalysis and the Scientific Council on "Catalysis and its industrial application" and also in all-union congresses and conferences at the highest level.

Beginning in 1961 on the initiative of Shimanskaya and Academician S. A. Giller, regular all-union symposia devoted to discussion of catalysis problems were held at Riga. In 1969 the first symposium was held on "Heterogeneous Catalysis in the Synthesis and Transformations of Heterocyclic Compounds." Subsequent conferences on this theme (1972, 1981, and 1987) invariably met with popularity among the specialists. 
Shimanskaya participated in many international seminars, symposia, and conferences (Brussels, Miami Beach, Torun, Warsaw. Budapest, Strasburg. Montpelier, etc.) and presented papers on the results obtained by the Riga catalysis workers. On her initiative, fruitful collaboration was established with the catalysis teams in the institutes of the Polish Academy of Sciences - the Institute of Catalysis and Surface Chemistry (Krakow) and the Institute of Physical Chemistry (Warsaw).

When in 1991 the only Catalysis Club in the Baltic States (soon to be admitted into the European Federation of National clubs) was founded in Riga, Shimanskaya was unanimously elected as the first president of this club.

Shimanskaya combined her investigations in the region of catalysis with work associated with organic analysis and, in particular, with the study of the new reagent dibepine (authors G. Dubur and G. Vanags), with the creation of methods for the analysis of furfural and medicinal products of the nitrofuran series, and with the development of new analytical reagents based on aldehydes of the pyridine series. Shimanskaya promoted the creation of the Laboratory of Organic Analysis at the Institute of Organic synthesis. The monograph of V. É. Égert, Ya. P. Stradyn, and M. V. Shimanskaya on "Methods for the Analytical Determination of Compounds of the 5-Nitrofuran Series" (Riga, 1968) was republished in English in London (Ann Arbor) in 1970. Researches into gas-liquid chromatography were commenced at the Institute of Organic Synthesis with the active support of Shimanskaya.

Shimanskaya worked actively on the editorial boards of the journals "Latvijas Kìmijas Żurnāls" (before 1992, "Izvestiya Akademii Nauk Latviiskogo SSR. Seriya Khimicheskaya") and "Latvijas Farmaceitiskais Žurnāls" (1989-1993). In 1978-1994 Shimanskaya led the Latvian Scientific Society of Pharmacists (founded in 1803).

In 1975 Shimanskaya defended a thesis on "Catalytic Synthesis and the Mechanism of the Catalytic Transformations of Oxygen- and Nitrogen-Containing Heterocyclic Compounds" and received the scientific degree of Doctor of Chemical Sciences. (In 1991 it was equated with the scientific degree Dr. habil. chem.) In 1988 Shimanskaya was given the title of professor, and in 1992 she was elected Honorary Member of the Latvian Academy of Sciences. For her scientific services, Shimanskaya was awarded the medals of Solomon Giller (1990), Arvid Kalnyn (1994), and David Ieronim Grindle (1995) and was also given the title of Honored Scientist and Technologist of the Latvian SSR (1982). In 1993-1995 Shimanskaya became one of the first $J$. Soros Emeritus Professors in Latvia.

By a resolution of the Senate of the Latvian Academy of Sciences of January 2, 1996. Shimanskaya was awarded (posthumously) the Gustav Vanag prize of the Latvian Academy of Sciences for a cycle of researches on "Nontraditional Methods of Catalysis in the Region of the Chemistry of Heterocyclic Compounds."

The memory of Prof. M. V. Shimanskaya and her services to the cause of the development of the chemistry of heterocyclic compounds, the creation of the Latvian Institute of Organic synthesis, and the education of a galaxy of students will occupy a worthy place in the history of Latvian chemistry.

\section{PRINCIPAL PAPERS OF M. V. SHIMANSKAYA}

1. M. V. Shimanskaya and V. A. Slavinskaya, The Analytical Determination of Furfural [in Russian], Izd. Akad. Nauk Latv. SSR (1961).

2. V. Egerts, A. Stradins, and M. Shimanska, Analysis of 5-Nitrofuran Derivatives [in Russian], Ann Arbor Science Publishers, London (1970).

3. M. B. Shimanskaya, Ya. F. Oshis, L. Ya. Leitis, I. G. Iovel', Yu. Sh. Gol'dberg, L. O. Golender, A. A. Anderson, and A. A. Avots, Advances of Heterogeneous Catalysis in the Chemistry of Heterocyclic Compounds [in Russian], M. V. Shimanskaya (ed.), Zinatne, Riga (1984).

4. M. V. Shimanskaya, Zh. G. Yuskovets, V. V. Stonkus, V. A. Slavinskaya, D. R. Kreile, and A. A. Avots, Catalytic Reactions of Furan Compounds [in Russian], M. V. Shimanskaya (ed.), Zinatne, Riga (1985). M. V. Shimanskaya, L. Ya. Leitis, R. A. Skolmeistere, I. G. Iovel', and L. O. Golender, Vanadium Catalysts for the Oxidation of Heterocyclic Compounds [in Russian], M. V. Shimanskaya (ed.), Zinatne, Riga (1990)

6. M. V. Shimanskaya, Ya. F. Oshis, and A. A. Anderson, "Catalytic synthesis of nitrogen-containing heterocycles," Khim. Geterotsikl. Soedin., 12, 1507 (1983)

7. L. Ya. Leitis, R. A. Skolmeistere, L. O. Golender, D. P. Yansone, and P. A. Meksh, "Reactivity of methyl derivatives of $\mathrm{N}$-containing heterocycles during vapor-phase catalytic oxidation," Khim. Geterotsikl. Soedin., No. 1, 75 (1986) 
8. I. Lovel, Yu. Goldberg, and M. Shymanska, "Hydroxymethylation of furan and its derivatives in the presence of cation-exchange resins," J. Mol. Catal., 57, 91 (1989).

9. Yu. Goldberg. E. Abele, and M. Shymanska, "Alkylation of 2-acetylpyrrole and 1-alkyl-2-acetylpyrroles under solid/liquid phase-transfer conditions," Synth. Commun., 21, No, 4, 557 (1991).

10. L. Leitis, R. Skolmeistere, I. Iovel, M. Shymanska, and E. Lukevics, "Selective catalytic oxidation of N-, O-, and S-methyl heterocyclic compounds, " in: B. Delmon and J. T. Yates (eds.), Studies in Surface Science and Catalysis, Vol. 72, Elsevier, Amsterdam-London-New York (1992), p. 117.

11. R. Skolmeistere, L. Leitis, M. Shymanska, and J. Stoch, "Influence of preparation conditions on activity and physical properties of $\mathrm{V}_{2} \mathrm{O}_{5}-\mathrm{SnO}_{2}$ catalyst for oxidative destruction of residual pyridine bases, "Catalysis Today. 17, 79 (1993).

12. E. Lukevics, M. Shymanska, L. Leitis, and I. Iovel, "Catalytic synthesis and reactions of nitrogen heterocycles," Chem. Heterocycl. Compds., No. 11-12, 1284 (1994). 